\title{
Registered report: The common feature of leukemia-associated IDH1 and IDH2 mutations is a neomorphic enzyme activity converting alpha-ketoglutarate to 2-hydroxyglutarate
}

\section{Oliver Fiehn ${ }^{1}$, Megan Reed Showalter ${ }^{1}$, Christine E Schaner-Tooley ${ }^{2}$, Reproducibility Project: Cancer Biology*}

${ }^{1}$ West Coast Metabolomics Center, University of California, Davis, Davis, United States; ${ }^{2}$ University of Louisville School of Medicine, Louisville, United States
REPRODUCIBILITY CANCER BIOLOGY

*For correspondence: stephen@ cos.io

Group author details: Reproducibility Project: Cancer Biology See page 18

Competing interest: See page 18

Funding: See page 18

Received: 30 October 2015 Accepted: 13 February 2016 Published: 26 February 2016

Reviewing editor: Jessica K Tyler, Weill Cornell Medical College, United States

(c) Copyright Fiehn et al. This article is distributed under the terms of the Creative Commons Attribution License, which permits unrestricted use and redistribution provided that the original author and source are credited.
Abstract The Reproducibility Project: Cancer Biology seeks to address growing concerns about reproducibility in scientific research by conducting replications of selected experiments from a number of high-profile papers in the field of cancer biology. The papers, which were published between 2010 and 2012, were selected on the basis of citations and Altmetric scores (Errington et al., 2014). This Registered Report describes the proposed replication plan of key experiments from "The common feature of leukemia-associated IDH1 and IDH2 mutations is a neomorphic enzyme activity converting alpha-ketoglutarate to 2-hydroxyglutarate" by Ward and colleagues, published in Cancer Cell in 2010 (Ward et al., 2010). The experiments that will be replicated are those reported in Figures 2, 3 and 5. Ward and colleagues demonstrate the mutations in isocitrate dehydrogenase 2 (IDH2), commonly found in acute myeloid leukemia (AML), abrogate the enzyme's wild-type activity and confer to the mutant neomorphic activity that produces the oncometabolite 2-hydroxyglutarate (2-HG) (Figures 2 and 3). They then show that elevated levels of 2-HG are correlated with mutations in IDH1 and IDH2 in AML patient samples (Figure 5). The Reproducibility Project: Cancer Biology is a collaboration between the Center for Open Science and Science Exchange and the results of the replications will be published by eLife. DOI: 10.7554/eLife.12626.001

\section{Introduction}

Mutations in the metabolic enzymes isocitrate dehydrogenase 1 (IDH1) and IDH2 genes, which catalyze the production of $\alpha$-ketoglutarate ( $\alpha-K G)$ from isocitrate, have been associated with numerous forms of cancer (Krell et alo, 2013) leading to exploration of how changes in their function could be linked to the development of tumors. All known mutations alter key residues in both proteins that decrease the enzyme's affinity for isocitrate, leading to the theory that the loss of IDH function perturbs the equilibrium of $\alpha-K G$, negatively affecting various $\alpha-K G$ dependent enzymes (Zhao et alo, 2009). However, work from the Thompson group determined that the tumor-associated mutations actually created a neomorphic function; rather than catalyzing the production of $\alpha-K G$, mutant IDH proteins produce the oncometabolite 2-hydroxyglutarate (2-HG) (Ward et al., 2012). Dang and colleagues first described this neomorphic function and demonstrated a correlation between 2-HG levels and glioma samples harboring IDH mutations (Dang et alo, 2009). In their 2010 Cancer Cell paper, Ward and colleagues further confirm these findings and extend the association of 2-HG levels and IDH mutations to acute myeloid leukemia (AML) (Ward et al., 2010). 
In Figure 2, Ward and colleagues transfected 293T cells with either wild type or mutant forms of IDH2. They assessed cell lysates for their ability to generate NDPH in the presence of isocitrate (Figure $2 \mathrm{~A}$ ) or to consume NADPH in the presence of $\alpha-K G$ (Figure 2B). Their data indicated that cells transfected with IDH2 ${ }^{\mathrm{WT}}$ generated $\mathrm{NADPH}$ in the presence of isocitrate, and did not consume much NADPH in the presence of $\alpha-K G$, consistent with its canonical function of converting isocitrate to $\alpha-K G$. However, IDH2 ${ }^{\mathrm{R} 172 \mathrm{~K}}$ displayed the opposite effect, indicating that it was able to consume $\mathrm{NADPH}$ in an $\alpha-K G$ dependent manner. These data were the first suggesting that the mutant form of IDH2 might have a neomorphic function. This key experiment will be replicated in Protocol 1.

In Figure 3, Ward and colleagues use gas-chromatography mass spectrometry (GC-MS) to identify a novel function of IDH2 $2^{\mathrm{R} 172 \mathrm{~K}}$. They identified a unique peak in the lysates of cells transfected with $\mathrm{IDH} 2^{\mathrm{R} 172 \mathrm{~K}}$ that corresponded to the retention time of the metabolite 2-hydroxyglutarate (2-HG). They confirmed the metabolite identity by mass spectrometry. These data provide evidence that the mutant form of IDH2 leads to 2-HG production. This key experiment will be replicated in Protocol 2.

In Figure 5, Ward and colleagues examined the correlation between AML patient samples carrying IDH mutations and the levels of 2-HG found in those samples. They showed that patient samples carrying IDH mutations contained higher levels of 2-HG than samples from patients with WT IDH genes. This key experiment will be replicated in Protocol 3.

Several groups' work has supported the results of Ward and colleagues, who themselves confirmed and extended their initial findings in subsequent reports (Ward et al., 2011; 2013). Leonardi and colleagues confirmed that mutant forms of IDH, specifically IDH1, did not perform the canonical forward reaction converting isocitrate to $\alpha-K G$ (Leonardi et al., 2012). Using magnetic resonance spectroscopy, Izquierdo-Garcia and colleagues confirmed that transfection of cells with mutant IDH forms increased the levels of 2-HG (Izquierdo-Garcia et al., 2015), while Jin and colleagues demonstrated similar findings for IDH1 and IDH2 mutants (Jin et al., 2011). Evaluating 2-HG levels in astrocytomas and gliomas harboring various IDH1 mutations, Pusch and colleagues also showed that any mutations in IDH1 correlated with increased levels of 2-HG in human patient samples (Pusch et al., 2014), a trend also observed by Juratli and colleagues (Juratli et al., 2013).

Discovery of IDH neomorphic function, resulting in the production of the 'oncometabolite' 2-HG, opened many avenues of research into how the production of excess 2-HG could impact tumorigenesis. Figueroa and colleagues expanded upon the foundation laid by Ward and colleagues and determined that excess 2-HG was correlated with changes in global methylation patterns (Figueroa et al., 2010). Xu and colleagues showed that 2-HG was able to competitively inhibit many $\alpha-K G$ dependent enzymes, including several histone demethylases, and that exogenous 1-HG was able to inhibit histone demethylation (Xu et al., 2011). Lu and colleagues also observed this correlation between 2-HG levels and perturbations in global histone methylation patterns, and went on to show that this resulted in impaired cellular differentiation (Lu et al., 2012).

\section{Materials and methods}

Unless otherwise noted, all protocol information was derived from the original paper, references from the original paper, or information obtained directly from the authors.

\section{Protocol 1: Assessing the $\alpha$-ketoglutarate dependent NADPH consumption of wild-type or mutant IDH2}

In this protocol, 293T cells are transfected with empty vector, IDH2 ${ }^{\mathrm{WT}}$, or IDH2 ${ }^{\mathrm{R} 172 \mathrm{~K}}$. Lysates are generated from these cells and their ability to produce NADPH from NADP+ and isocitrate is assayed (Figure 2A). The same lysates are also assayed for their ability to consume NADPH in the presence of $0.5 \mathrm{mM} \alpha$-ketoglutarate $(\alpha-\mathrm{KG})$ (Figure $2 \mathrm{~B}$ ). Expression of the transfected protein will be confirmed by Western blot (Figure 2C).

Sampling

Oxidative and reductive activity (Figures $2 \mathrm{~A}$ and $\mathrm{B}$ ):

- Experiment has three conditions. Each will be performed with seven biological replicates and three technical replicates of each condition at each time point for a final power of at least $80 \%$. 
- Condition 1: 293T cells expressing IDH2 $2^{W T}$

- Condition 2: 293T cells expressing IDH2 $2^{R 172 K}$

- Condition 3: 293T cells expressing empty pCDNA3 vector

o Each lysate will be assessed for cell's ability to reduce $\mathrm{NADP}^{+}$and oxidate NADPH

o See Power Calculations section for details.

Confirmatory Western Blot (Figure 2C)

- This is a quality control experiment and is not being powered to detect a specific effect size. Western blots will be performed alongside each biological replicate.

- Western blotting of each lysate will be performed for the following proteins

- IDH2

- IDH1

- Actin [additional]

\section{Materials and reagents}

\begin{tabular}{|c|c|c|c|c|}
\hline Reagent & Type & Manufacturer & Catalog \# & Comments \\
\hline 293T cells & Cells & ATCC & CRL-3216 & Original source unspecified \\
\hline $\begin{array}{l}\text { Dulbecco's modified } \\
\text { Eagle's medium } \\
\text { (DMEM) }\end{array}$ & Media & Invitrogen & 11965118 & Original unspecified \\
\hline FBS & Reagent & Hyclone & SH30071.03 & Replaces FBS from CellGro \\
\hline IDH2 ${ }^{W T}$ ORF in pCMV6 & Plasmid & Origene & RC201152 & \\
\hline IDH2 ${ }^{\mathrm{R} 172 \mathrm{~K}} \mathrm{ORF}$ in $\mathrm{pCMV6}$ & Plasmid & Origene & RC400103 & \\
\hline pCDNA3 & Plasmid & Invitrogen & V790-20 & \\
\hline Lipofectamine 2000 & Reagent & Invitrogen & 11668027 & \\
\hline $\begin{array}{l}\text { M-Per Mammalian protein } \\
\text { extraction reagent }\end{array}$ & Reagent & Pierce & 78503 & \\
\hline Aprotinin & Reagent & Sigma & 248614 & \multirow{4}{*}{$\begin{array}{l}\text { Original protease } \\
\text { inhibitor cocktail } \\
\text { unspecified }\end{array}$} \\
\hline AEBSF & Reagent & EMD Millipore & 101500-100MG & \\
\hline Leupeptin & Reagent & Sigma & L2884-100mg & \\
\hline Pepstatin A & Reagent & EMD Millipore & 516481-100MG & \\
\hline $\mathrm{NaOV}$ & Reagent & Sigma & 450243-50G & \multirow[t]{2}{*}{ Original unspecified } \\
\hline $\mathrm{NaF}$ & Reagent & Sigma & 215309-50G & \\
\hline Sonicator & Equipment & VCR & $75 \mathrm{HT}$ & Original unspecified \\
\hline $\begin{array}{l}\text { Refrigerated } \\
\text { microcentrifuge }\end{array}$ & Equipment & Labnet International, Inc & PrismR & Original unspecified \\
\hline Tris- $\mathrm{HCl}$ & Reagent & BioRad & BR0011 & Original unspecified \\
\hline $\mathrm{MnCl} 2$ & Reagent & M87-100 & Fisher & Original unspecified \\
\hline EDTA & Reagent & WWR & EM-4050 & Original unspecified \\
\hline B-NADP+ & Reagent & MP Biomedicals & ICN10116680 & Original unspecified \\
\hline B-NADPH & Reagent & Sigma & 10107824001 & Original unspecified \\
\hline D-(+)-threo-isocitrate & Reagent & Sigma & 11252 & \\
\hline Spectrophotometer & Instrument & Molecular Devices & Filter Max F5 Multi-mode Microplate Reader & Original unspecified \\
\hline $\begin{array}{l}\text { 6-well tissue } \\
\text { culture plates }\end{array}$ & Materials & E\& K Scientific & 27160 & Original unspecified \\
\hline 96 well plates & Materials & Fisher (Costar) & $07-200-656$ & Original unspecified \\
\hline Tric-HCl & Reagent & BioRad & BR0011 & Original unspecified \\
\hline
\end{tabular}

Continued on next page 
Continued

\begin{tabular}{|c|c|c|c|c|}
\hline Reagent & Type & Manufacturer & Catalog \# & Comments \\
\hline Glycerol & Reagent & WWR & EM-4760 & Original unspecified \\
\hline B-mercaptoethanol & Reagent & Sigma & M6250-250mL & Original unspecified \\
\hline $\begin{array}{l}\text { Sodium dodecyl sulfate } \\
\text { (SDS) }\end{array}$ & Reagent & Sigma & L3771-100G & Original unspecified \\
\hline Bromophenol blue & Reagent & Sigma & B0126-25G & Original unspecified \\
\hline Protogel & Reagent & Fisher/National Diagnostics & 50-899-90119 & Original unspecified \\
\hline APS & Reagent & Sigma & 248614 & Original unspecified \\
\hline TEMED & Reagent & Fisher & BP150-100 & Original unspecified \\
\hline nitrocellulose & Materials & BioRad & $162-0112$ & Original unspecified \\
\hline $\begin{array}{l}\text { Anti-IDH2 antibody } \\
\text { (mouse monoclonal) }\end{array}$ & Primary Antibody & Abcam & ab55271 & \\
\hline $\begin{array}{l}\text { Anti-IDH1 antibody } \\
\text { (goat polyclonal) }\end{array}$ & Primary Antibody & Santa Cruz & sc49996 & \\
\hline $\begin{array}{l}\text { Anti-Actin antibody } \\
\text { (rabbit monoclonal)- } \\
\text { HRP conjugated }\end{array}$ & Primary Antibody & Cell Signaling & 12620 & Not included in original. \\
\hline $\begin{array}{l}\text { ECL Mouse IgG, } \\
\text { HRP-linked whole Ab } \\
\text { (from sheep) }\end{array}$ & Secondary Antibody & GE Healthcare & NA931V & \\
\hline $\begin{array}{l}\text { HRP conjugated rabbit } \\
\text { anti-goat antibody }\end{array}$ & Secondary Antibody & Invitrogen & 811620 & Original unspecified \\
\hline \multirow[t]{2}{*}{ Protein ladders } & \multirow[t]{2}{*}{ Reagent } & Cell Signaling Tech. & 7727L & Original unspecified \\
\hline & & Gold Biotech & p007-1500 & Original unspecified \\
\hline $\mathrm{ECL}$ reagent & Reagent & Fisher Scientific & PI34096 & Original unspecified \\
\hline Endo-free maxiprep kit & Reagent & Qiagen & 12362 & Original unspecified \\
\hline$\alpha$-ketoglutarate & Reagent & Sigma & 75892-25G & Original unspecified \\
\hline DC Protein Assay Kit & Kit & BioRad & 5000112 & Original unspecified \\
\hline Alpha innotech imager & Equipment & Alpha Innotech & Alphaimager 2200 & \\
\hline sodium azide & Reagent & Sigma & S2002-5G & Original Unspecified \\
\hline Ponceau stain & Reagent & Quality Biological & $50-751-6798$ & Additional reagent \\
\hline
\end{tabular}

Procedure

Notes

- $293 \mathrm{~T}$ cells are grown in DMEM supplemented with $10 \% \mathrm{FBS}$ at $37^{\circ} \mathrm{C}$ in $5 \% \mathrm{CO}_{2}$

- Cells will be sent for STR profiling and mycoplasma testing.

1. Confirm insert identity by sequencing.

a. Origene clones are shipped with two sequencing primers.

2. Sub-clone IDH2 $2^{\mathrm{WT}}$ and IDH2 $2^{\mathrm{R} 172 \mathrm{~K}}$ from the Origene pCMV6-Entry vectors into pcDNA3.

a. Confirm insert identity by sequencing.

b. Confirm vector integrity by agarose gel electrophoresis.

3. Grow up and use an endo-free maxiprep kit to prep the following vectors:
a. pcDNA3
b. PcDNA3-IDH2 $2^{\mathrm{WT}}$
c. PcDNA3-IDH2 $2^{\mathrm{R} 172 \mathrm{~K}}$

4. Seed $0.25-1 \times 10^{6} 293$ T cells per well of a 6-well plate in growth medium without antibiotics.

a. Grow overnight.

b. Confirm cells at 70-80\% confluency by light microscopy at time of transfection.

5. Transfect $293 \mathrm{~T}$ cells with pcDNA3, pcDNA3-IDH2 ${ }^{\mathrm{WT}}$, pcDNA3-IDH2 ${ }^{\mathrm{R} 172 \mathrm{~K}}$ with Lipofectamine 2000 according to manufacturer instructions for a 6-well plate. 
a. As per manufacture's instructions $1 \mu \mathrm{g}$ plasmid DNA per well in a 6-well plate for 70 $80 \%$ confluent $293 \mathrm{~T}$ cells.

b. Transfect 1 well (or plate if reaction needs to be scaled up) for each construct

i. This will be one biological replicate

6. $48 \mathrm{hr}$ after transfection, remove medium from cells, wash with PBS, and lyse in $1 \mathrm{ml} /$ well of mammalian protein extraction reagent containing protease inhibitor cocktail (aprotinin, AEBSF, leupeptin and pepstatin $A$, all at 1:1000) and phosphatase inhibitor cocktails (NaOV, Pepstatin A, Leupeptin, AEBSF, NaF, aprotinin) at $4^{\circ} \mathrm{C}$ or on ice.

7. Collect lysate and sonicate.

a. Perform test for optimal conditions as follows.

i. Sonication for $5 \mathrm{~min}$

ii. Sonication for $10 \mathrm{~min}$

b. Centrifuge lysate in refrigerated microcentrifuge at $14000 \times \mathrm{xg}$ at $4^{\circ} \mathrm{C}$ for $10 \mathrm{~min}$.

c. Collect supernatants and measure the protein concentration of each using the DC Protein Assay Kit II according to the manufacturer's instructions.

d. Will need $>50 \mu \mathrm{g}$ total protein to proceed

i. If $50 \mu \mathrm{g}$ total protein is not achieved the reaction will be scaled to a $25 \mathrm{~cm}$ plate. These conditions will be used for the subsequent replicates without any further optimization.

ii. If further optimization is needed, the experiment will not proceed to step 7 until this is achieved.

e. Aliquot lysate protein for measuring IDH oxidative (Step 9) and reductive activity (step 10) and for examining expression of IDH2 ${ }^{\mathrm{WT}}, \mathrm{IDH} 2^{\mathrm{R} 172 \mathrm{~K}}$ by western blot (step 11).

8. Measuring IDH oxidative activity:

a. Mix $0.3 \mu \mathrm{g}$ of each protein lysate with $200 \mu \mathrm{l}$ of assay buffer solution in a 96-well plate. Each condition should be plated in triplicate.

i. Assay buffer solution: $100 \mathrm{mM}$ Tris- $\mathrm{HCl}$ buffer $(\mathrm{pH} 7.5), 1.3 \mathrm{mM} \mathrm{MnCl}, 0.33 \mathrm{mM}$ EDTA, $0.1 \mathrm{mM}$ B-NADP ${ }^{+}, 0.1 \mathrm{mM}$ D-(+)-threo-isocitrate

ii. Include buffer lacking lysate protein to determine background reading.

b. Put mixtures in spectrometer and measure absorbance at $340 \mathrm{~nm}$ every $20 \mathrm{~s}$ for $30 \mathrm{~min}$.

c. Use absorbance readings at 5 min intervals for analysis.

i. An exploratory investigation of all data will be used in the analysis as well.

9. Measuring IDH reductive activity:

a. Mix $3 \mu \mathrm{g}$ of each protein lysate with $200 \mu \mathrm{l}$ of assay buffer solution in a 96-well plate. Each condition should be plated in triplicate.

i. Assay buffer solution: $100 \mathrm{mM}$ Tris- $\mathrm{HCl}$ buffer (ph 7.5), $1.3 \mathrm{mM} \mathrm{MnCl}, 0.01 \mathrm{mM} \mathrm{B-}$ $\mathrm{NADPH}, 0.5 \mathrm{mM} \alpha$-ketoglutarate

ii. Include buffer lacking lysate protein to determine background reading.

b. Put mixtures in spectrometer and measure absorbance at $340 \mathrm{~nm}$ every $20 \mathrm{~min}$ for $3 \mathrm{hr}$.

10. Western blot to confirm protein expression:

a. Add sample buffer and boil lysates to prepare for loading.

i. Sample buffer: $0.5 \mathrm{~mL} 1 \mathrm{M}$ TrisCl, pH 6.8, $1 \mathrm{~mL}$ glycerol, $0.5 \mathrm{~mL}$ ß-mercaptoethanol, $0.24 \mathrm{~g}$ SDS, $0.1 \mathrm{~mL} 1 \%$ bromophenol blue.

ii. Add $30 \mu \mathrm{g}$ of protein per well by diluting protein to same concentrations (based on protein quantification results) in $10 \mu \mathrm{L}$ of lyse buffer and added $20 \mu \mathrm{L}$ of sample buffer

iii. Place at $65^{\circ} \mathrm{C}$ for $15 \mathrm{~min}$.

b. Separate 20-30 $\mu \mathrm{g}$ of protein per lane on an 8\% SDS-PAGE gel with protein ladder.

i. Run through the stacker at $45 \mathrm{mAmp} / \mathrm{gel}$, then increase to $300 \mathrm{~V}$ for $3 \mathrm{hr}$.

c. Transfer to nitrocellulose membrane.

i. Transfer at $100 \mathrm{~A}$ for $1 \mathrm{hr} 40 \mathrm{~min}$ in $2.5 \mathrm{mM}$ Tris, $19 \mathrm{mM}$ glycine in $20 \%$ methanol.

ii. Wash membrane in deionized water then wash in 1X TBST.

iii. Confirm protein transfer with Ponceau stain.

d. Block membrane with $5 \%$ milk/0.2\% azide in TBST for 30 min at room temperature.

e. Incubate with the following primary antibodies using the manufacturer's recommended dilution. Following antibodies will be probed at one time

i. Mouse anti-IDH2; $37 \mathrm{kDa}$

ii. Goat anti-IDH1; $47 \mathrm{kDa}$

f. Incubate with appropriate secondary antibodies using manufacture's recommended dilutions

i. HRP-conjugated sheep anti-mouse 
ii. HRP-conjugated rabbit anti-goat

1. The anti-actin antibody is HRP conjugated and a secondary antibody incubation is not necessary.

g. Treat membranes with ECL reagent according to manufacturer's recommendations and image.

h. Between antibody incubations, inactivate HRP activity by incubating with a final concentration of $1 \mathrm{mM}$ sodium azide in blocking buffer.

i. Shake at room temp for $1 \mathrm{hr}$.

ii. Wash membrane $3 \times 5 \mathrm{~min}$ in $1 \times$ TBST.

iii. Incubate with ECL reagent as directed by the manufacturer and image at a time point of at least 5 min to confirm HRP inactivation

iv. Save blank image

i. Incubate with Rabbit anti-actin-HRP; $45 \mathrm{kDa}$ [additional] to evaluate loading control

j. Treat membranes with ECL reagent according to manufacturer's recommendations and image.

11. Repeat steps 6-9 independently six additional times.

\section{Deliverables}

- Data to be collected:

- Sequencing reads and agarose gel images confirming vector identity and integrity

- pcDNA3

- $\quad$ PCDNA3-IDH2 $2^{\mathrm{WT}}$

- pcDNA3-IDH2 ${ }^{\mathrm{R} 172 \mathrm{~K}}$

- Raw data from plate reader for reduced $\mathrm{NADP}^{+}$and oxidated NADPH

- Background subtracted readings

- Full western images, including ladder

- Ponceau stains confirming protein transfer

- ECL negative control from step 9-hr

Confirmatory analysis plan

Statistical Analysis of the Replication Data:

- Note: At the time of analysis, we will perform the Shapiro-Wilk test and generate a quantilequantile plot to assess the normality of the data. We will also perform Levene's test to assess homoscedasticity. If the data appears skewed, we will perform the appropriate transformation to proceed with the proposed statistical analysis. If this is not possible, we will perform the equivalent non-parametric Wilcoxon-Mann-Whitney test.

- For oxidative activity assays:

- Bonferroni corrected ANOVA followed by two-tailed Bonferroni corrected planned contrasts:

- Vector vs. IDH2 ${ }^{\mathrm{WT}}$

- Vector vs. IDH2 $2^{\mathrm{R} 172 \mathrm{~K}}$

- For reductive activity assays

- Bonferroni corrected ANOVA followed by two-tailed Bonferroni corrected planned contrasts:

- Vector vs. IDH2 $2^{\mathrm{WT}}$

- Vector vs. IDH2 $2^{\mathrm{R} 172 \mathrm{~K}}$

- Western blot:

- This is a quality control experiment and is not powered to detect a specific effect.

- Meta-analysis of original and replication attempt:

- This replication attempt will perform the statistical analysis listed above, compute the effects sizes, compare them against the reported effect size in the original paper and use a meta-analytic approach to combine the original and replication effects, which will be presented as a forest plot. 
Known differences from the original study

Although not performed by the original authors, actin was added as internal loading control for Western blots and will be added to the resulting data. Details of the Western blot protocol and possible stripping/sodium azide treatment were unspecified; information was added by the replicating lab. The details of the transfection specifics were unspecified and that information is provided by the replicating lab. Additionally, these experiments will be conducted in 6-well dishes, however, if total protein yield is not sufficient, the replicating lab will scale up to $25 \mathrm{~cm}$ dishes.

Provisions for quality control

All data obtained from the experiment - raw data, data analysis, control data, and quality control data - will be made publicly available, either in the published manuscript or as an open access dataset available on the Open Science Framework (https://osf.io/8|4ea/).

- STR profiling and mycoplasma testing results

- Sequencing reads and agarose gel images confirming vector identity and integrity

- Ponceau stains confirming protein transfer for Western Blot

- Confirmation of HRP inactivation prior to proceeding with the following antibodies.

\section{Protocol 2: Production of 2-HG from IDH2 WT and mutant transfected cells}

In this protocol, the production of 2-HG from 293T cells transfected with vectors expressing IDH2 ${ }^{\mathrm{WT}}$ or IDH2 $2^{\mathrm{R} 172 \mathrm{~K}}$ is measured by gas chromatography-mass spectrometry (as seen in Figures $3 \mathrm{~A}-\mathrm{C}$ ). The amount of 2-HG relative to glutamate is quantified, as seen in Figure 3D.

\section{Sampling}

- Experiment will be performed with at least three biological replicates for a final power of at least $80 \%$. The original data are qualitative, thus to determine an appropriate number of replicates to initially perform, sample sizes based on a range of potential variance was determined.

- See Power Calculations section for details.

- Experiment has three conditions:

- Condition 1:293T cells expressing IDH2 $2^{\mathrm{WT}}$

- Condition 2: 293T cells expressing IDH2 $2^{\mathrm{R} 172 \mathrm{~K}}$

- Condition 3: 293T cells expressing empty pCDNA3 vector

- For each condition, lysates will be analyzed for 2-HG/glutamate levels

Materials and reagents

\begin{tabular}{lllll} 
Reagent & Type & Manufacturer & Catalog \# & Comments \\
\hline 293T cells & Cells & ATCC & CRL-3216 & Original source unspecified \\
\hline $\begin{array}{l}\text { Dulbecco's modified } \\
\text { Eagle's medium } \\
\text { (DMEM) }\end{array}$ & Media & Invitrogen & 11965118 & Original unspecified \\
\hline Pen/Strep & Reagent & Fisher & 15140-122 & Original unspecified \\
\hline FBS & Reagent & Hyclone & SH30071.03 & Replaces FBS from CellGro \\
\hline pcDNA-IDH2 ${ }^{\text {WT }}$ & Plasmid & $\begin{array}{l}\text { Generated in } \\
\text { Protocol 1 }\end{array}$ & & \\
\hline PcDNA-IDH2 ${ }^{\text {R172K }}$ & Plasmid & $\begin{array}{l}\text { Generated in } \\
\text { Protocol 1 }\end{array}$ & & \\
\hline Lipofectamine 2000 & Reagent & Invitrogen & 11668027 & Original unspecified \\
\hline Methanol & Reagent & Fisher & A452SK-4 &
\end{tabular}

Continued on next page 
Continued

\begin{tabular}{|c|c|c|c|c|}
\hline Reagent & Type & Manufacturer & Catalog \# & Comments \\
\hline $\begin{array}{l}\text { Refrigerated } \\
\text { centrifuge }\end{array}$ & Equipment & Labnet International, Inc & PrismR & Original unspecified \\
\hline Nitrogen gas & Reagent & Generated in lab & & Original unspecified \\
\hline $\begin{array}{l}\text { AG-1 X8 100-200 } \\
\text { anion exchange } \\
\text { column }\end{array}$ & Reagent & Bio-Rad & $731-6211$ & Poly-Prep Columns, AG 1-X8, chloride form \\
\hline $\mathrm{HCl}$ & Reagent & Fisher & SA56-1 & Original unspecified \\
\hline $\begin{array}{l}\mathrm{N} \text {-methyl-N-tert- } \\
\text { butyldimethylsily } \\
\text { trifluoroacetamide } \\
\text { (MTBSTFA; Regis) }\end{array}$ & Reagent & Regis & $1-270243-200$ & \\
\hline $\begin{array}{l}\text { Gas Chromatograph with } \\
\text { an HP-5MS capillary column } \\
\text { and Mass selective } \\
\text { detector }\end{array}$ & Equipment & $\begin{array}{l}\text { Agilent } 7890 \mathrm{~A} \\
\text { with } 7693 \text { Autosampler }\end{array}$ & & \\
\hline Cold trap concentrator & Equiptment & Labconco Centrivap & & \\
\hline $\mathrm{R}(-)-2-\mathrm{HG}$ & Reagent & Sigma-Aldrich & H8378-100MG & Original unspecified \\
\hline
\end{tabular}

\section{Procedure}

\section{Notes}

- $293 \mathrm{~T}$ cells grown in DMEM supplemented with $10 \% \mathrm{FBS}$ at $37^{\circ} \mathrm{C}$ in $5 \% \mathrm{CO}_{2}$.

- All cells will be sent for STR profiling and mycoplasma testing

1. Seed $0.25-1 \times 10^{6} 293 \mathrm{~T}$ cells per well of a 6-well plate in growth medium without antibiotics.

a. Grow overnight.

b. Confirm cells at $70-80 \%$ confluence by light microscopy at time of transfection.

2. Transfect $293 \mathrm{~T}$ cells with pCDNA3, pCDNA3-IDH2 ${ }^{\mathrm{WT}}$, or pCDNA3-IDH2 ${ }^{\mathrm{R} 172 \mathrm{~K}}$ with Lipofectamine 2000 according to manufacturer instructions.

a. Transfect $1 \mu \mathrm{g}$ of plasmid DNA per well in 6-well plate at $70-80 \%$ confluence.

b. Generate duplicate plates for each transfection:

i. Harvest one plate at $24 \mathrm{hr}$.

ii. Harvest one plate at $48 \mathrm{hr}$.

3. $24 \mathrm{hr}$ later, replace with fresh media with $1 \times$ pen/strep

4. 24 or $48 \mathrm{hr}$ later, gently remove medium from proliferating cells.

a. Note: from this point on this protocol contains information as described in (Bennett et al., 2008).

5. Rapidly quench cells with $1-2 \mathrm{ml}$ per well of $-80^{\circ} \mathrm{C}$ methanol.

a. Chill cells to $-80^{\circ} \mathrm{C}$ and incubate at $-80^{\circ} \mathrm{C}$ for $15 \mathrm{~min}$.

6. Scrape cells off the dish and transfer the cell suspension to a $15 \mathrm{ml}$ conical tube.

a. Centrifuge for $5 \mathrm{~min}$ at $2000 \mathrm{xg}$ at $4^{\circ} \mathrm{C}$ to pellet cellular debris.

b. Transfer supernatant to a fresh $15 \mathrm{ml}$ tube.

7. Resuspend the pellet in $500 \mu \mathrm{l}$ of $-80^{\circ} \mathrm{C} 80 \%$ methanol in water by vortexing.

a. Incubate at $4^{\circ} \mathrm{C}$ for $15 \mathrm{~min}$.

b. Centrifuge for $5 \mathrm{~min}$ at $2000 \times \mathrm{xg}$ at $4^{\circ} \mathrm{C}$.

c. Combine supernatant with supernatant from Step $6 b$.

d. Repeat step 7 for a third round of extraction and combine all supernatants.

8. Evaporate to dryness using a cold trap concentrator.

9. Elute through an AG-1 X8 100-200 anion exchange resin according to the manufacturer's instructions.

a. Wash with five column volumes of wash buffer.

b. Elute in $3 \mathrm{~N} \mathrm{HCl}$.

10. Evaporate to dryness using cold trap concentrator

11. Redissolve sample in MSTFA + FAME.

a. Prepare $40 \mathrm{mg} / \mathrm{mL}$ Methoxyamine hydrochloride (MeOX) solution in pyridine. 
i. Weigh out methoxyamine hydrochloride in $1.5 \mathrm{ml}$ Eppendorf tube on balance and add appropriate amount of pyridine.

b. Vortex MeOX solution and sonicate at $60^{\circ} \mathrm{C}$ for $15 \mathrm{~min}$ to dissolve.

c. Add $10 \mu \mathrm{l}$ of $40 \mathrm{mg} / \mathrm{ml} \mathrm{MeOX}$ solution to each dried sample.

d. Shake at maximum speed at $60^{\circ} \mathrm{C}$ for $1 \mathrm{hr}$.

e. To $1 \mathrm{ml}$ of MSTFA, add $10 \mu$ of FAME marker.

i. Vortex for $10 \mathrm{~s}$.

f. Add $91 \mu$ l of MSTFA + FAME mixture to each sample and standard. Cap immediately.

i. Shake at maximum speed at $37^{\circ} \mathrm{C}$.

g. Transfer contents to glass vials with micro-inserts and cap immediately.

i. Submit to GCTOF MS analysis.

12. Inject samples into GC-MS.

a. Operate the detector in spitless mode using electron impact ionization.

i. lonizing voltage: $-70 \mathrm{eV}$

ii. Electron multiplier: $1060 \mathrm{~V}$

b. GC temperature ramp:

i. Hold at $100^{\circ} \mathrm{C}$ for $3 \mathrm{~min}$.

ii. Ramp to $230^{\circ} \mathrm{C}$ at $4^{\circ} \mathrm{C} / \mathrm{min}$.

iii. Hold for $4 \mathrm{~min}$.

iv. Ramp to $300^{\circ} \mathrm{C}$.

v. Hold for 5 min.

c. Record mass range of 50-500 amu and record 2.71 scans $/ \mathrm{s}$.

13. Repeat steps 1-12 independently three additional times.

\section{Deliverables}

- Data to be collected:

- $24 \mathrm{hr}$ samples:

- GC traces for all samples run

- Close-up of the time range showing metabolite abundance for aspartate, glutamate, and 2-HG for cells transfected with IDH2 ${ }^{\mathrm{WT}}$ (Figure $3 \mathrm{~A}$ ) and cells transfected with IDH2 $2^{\mathrm{R} 172 \mathrm{~K}}$ (Figure 3B).

- Mass spectrum confirmation of metabolite identity as 2-HG.

- 48 hr run

- GC traces for all samples run

Close-up of the time range showing metabolite abundance for aspartate, glutamate, and 2-HG for cells transfected with IDH2 ${ }^{\mathrm{WT}}$ (Figure $3 \mathrm{~A}$ ) and cells transfected with IDH2 ${ }^{\mathrm{R} 172 \mathrm{~K}}$ (Figure $3 \mathrm{~B}$ ).

- Quantification of the relative intensity of the 2-HG signal to the glutamate signal, graphed as seen in Figure 3D.

\section{Confirmatory analysis plan}

- Statistical Analysis of the Replication Data:

- Note: At the time of analysis, we will perform the Shapiro-Wilk test and generate a quantilequantile plot to assess the normality of the data. We will also perform Levene's test to assess homoscedasticity. If the data appears skewed, we will perform the appropriate transformation to proceed with the proposed statistical analysis. If this is not possible, we will perform the equivalent non-parametric test.

- Two-way ANOVA performed on 2-HG/glutamate ratios followed by Fisher's LSD for the following comparisons:

- Vector vs. IDH2 $2^{\mathrm{WT}}$

- IDH2 ${ }^{\mathrm{WT}}$ vs. IDH2 $2^{\mathrm{R} 172 \mathrm{~K}}$

o Analyses will be performed on both 24 and 48 hr runs.

- Meta-analysis of original and replication attempt:

- The replication data will be presented as a mean with $95 \%$ confidence intervals and will include the original data point, calculated directly from the graph, as a single point on the same plot for comparison. 
Known differences from the original study

- The GC-MS sample preparation protocol was modified by the replicating lab including a shaking incubation step at 11f. However, this protocol was taken from Bennett et al. which the authors reference in the original manuscript.

Provisions for quality control

All data obtained from the experiment - raw data, data analysis, control data and quality control data - will be made publicly available, either in the published manuscript or as an open access dataset available on the Open Science Framework (https://osf.io/814ea/).

- STR profiling and mycoplasma testing results.

- Mass spectrum of the metabolite peak for derivatized $2 \mathrm{HG}$ to confirm identity.

\section{Protocol 3: Assessing the correlation of IDH status with 2-HG levels in samples from patients with AML}

In this protocol, samples from patients with acute myeloid leukemia (AML) are examined for their IDH mutational status and their level of 2-HG, as seen in Figure 5.

\section{Sampling}

- This experiment will use four samples per group for a final power of at least $80 \%$.

- See Power Calculations section for details.

- This experiment has three genetically distinct groups:

- AML patients with no IDH mutations

- AML patients with mutant IDH1

- AML patients with mutant IDH2, including both R172K and R1400 mutants

- All samples will come from Roswell Park Cancer Institute and are ficoll separated in media with 10\% DMSO and prescreened for IDH genotypic status.

- Each patient sample will be assessed for their ratio of 2-HG/glutamate.

Materials and reagents

\begin{tabular}{|c|c|c|c|c|}
\hline Reagent & Type & Manufacturer & Catalog \# & Comments \\
\hline $\begin{array}{l}\text { Samples of peripheral } \\
\text { blood, bone marrow, } \\
\text { or pheresis from patients } \\
\text { with karyotypically normal AML }\end{array}$ & Patient sample & NA & NA & Banked RPCI samples \\
\hline DMSO & Reagent & Fisher & BP231-1 & Original Unspecified \\
\hline Methanol & Reagent & Fisher & A452SK-4 & Original unspecified \\
\hline $\begin{array}{l}\text { Refrigerated } \\
\text { centrifuge }\end{array}$ & Equipment & Labnet International, Inc & PrismR & Original unspecified \\
\hline $\begin{array}{l}\text { AG-1 X8 100-200 } \\
\text { anion exchange column }\end{array}$ & Reagent & Bio-Rad & $731-6211$ & $\begin{array}{l}\text { Poly-Prep Columns, AG 1-X8, } \\
\text { chloride form }\end{array}$ \\
\hline $\mathrm{HCl}$ & Reagent & Fisher & SA56-1 & Original unspecified \\
\hline $\begin{array}{l}\mathrm{N} \text {-methyl-N-tert- } \\
\text { butyldimethylsily } \\
\text { trifluoroacetamide } \\
\text { (MTBSTFA; Regis) }\end{array}$ & Reagent & Regis & $1-270243-200$ & \\
\hline $\begin{array}{l}\text { Gas Chromatograph with an } \\
\text { HP-5MS capillary column and Mass selective detector }\end{array}$ & Equipment & $\begin{array}{l}\text { Agilent } 7890 \text { A with } \\
7693 \text { Autosampler }\end{array}$ & & \\
\hline $\begin{array}{l}\text { Cold trap } \\
\text { concentrator }\end{array}$ & Equiptment & Labconco Centrivap & & \\
\hline
\end{tabular}




\section{Procedure}

1. GC-MS analysis of 2-HG levels.

a. If using frozen cells, warm cells to $37^{\circ} \mathrm{C}$ in a $37^{\circ} \mathrm{C}$ water bath for $10 \mathrm{~min}$

b. Centrifuge cells for $5 \mathrm{~min}$ at $1000 x \mathrm{~g}$ to form a pellet

i. If necessary, transfer cells to a conical or microcentrifuge tube

c. Gently remove freezing medium from MNCs

d. Proceed with metabolite extraction and GC-MS analysis as detailed in protocol 2 Steps 5 through 12.

e. For each sample, divide the GC signal intensity of their 2-HG peak by the signal intensity of their glutamate peak and graph.

\section{Deliverables}

- Data to be collected:

- Tabulated patient data (age, sex, IDH mutation status, 2-HG/glutamate ratio) (as seen in Table 1)

- GC traces for all samples

- Graph of 2-HG/glutamate ratio for samples by mutational status, as seen in Figure 5C.

\section{Confirmatory analysis plan}

- Statistical Analysis of the Replication Data:

- Note: The authors report WT IDH ratios were less than $1 \%$ which we are using as the constant for the comparisons below.

- Bonferroni Correct one-sample t-test for 3 comparisons (alpha corrected for 2 test groups $=0.025$ )

- Constant vs. IDH1 $1^{\text {mutant }}$

- Constant vs. IDH2 mutant

- Constant vs IDH1/2 mutants

- Meta-analysis of original and replication attempt:

- This replication attempt will perform the statistical analysis listed above, compute the effects sizes, compare them against the reported effect size in the original paper and use a meta-analytic approach to combine the original and replication effects, which will be presented as a forest plot.

\section{Known differences from the original study}

- The GC-MS sample preparation protocol was modified by the replicating lab including a shaking incubation step at $11 \mathrm{f}$, protocol 2. However, this protocol was taken from Bennett et al. which the authors reference in the original manuscript.

Provisions for quality control

All data obtained from the experiment - raw data, data analysis, control data and quality control data - will be made publicly available, either in the published manuscript or as an open access dataset available on the Open Science Framework (https://osf.io/8/4ea/). This includes confirmation of the GCMS peaks and elution times as well as MS QC data.

\section{Power calculations}

For details of power calculations, see spreadsheet and additional files at https://osf.io/9jkpg/

Protocol 1

Summary of original data estimated from graph reported in Figure 2A:

- $\mathrm{SD}$ was calculated using formula $S D=S E M *(S Q R T n=3)$. 


\begin{tabular}{|c|c|c|c|c|}
\hline Sample & Time & Mean & SEM & SD \\
\hline \multirow[t]{7}{*}{$\mathrm{IDH} 2^{\mathrm{WT}}$} & 0 & 0 & 0.0820 & 0.1421 \\
\hline & 5 & 0.225 & 0.0820 & 0.1421 \\
\hline & 10 & 0.45 & 0.1025 & 0.1776 \\
\hline & 15 & 0.679 & 0.1538 & 0.2664 \\
\hline & 20 & 0.917 & 0.1974 & 0.3419 \\
\hline & 25 & 1.129 & 0.2512 & 0.4352 \\
\hline & 30 & 1.342 & 0.3 & 0.5196 \\
\hline \multirow[t]{7}{*}{$\mathrm{IDH} 2^{\mathrm{R} 172 \mathrm{~K}}$} & 0 & 0 & 0.0820 & 0.1421 \\
\hline & 5 & 0.038 & 0.0820 & 0.1421 \\
\hline & 10 & 0.062 & 0.0820 & 0.1421 \\
\hline & 15 & 0.062 & 0.0820 & 0.1421 \\
\hline & 20 & 0.062 & 0.0820 & 0.1421 \\
\hline & 25 & 0.1 & 0.0820 & 0.1421 \\
\hline & 30 & 0.096 & 0.0820 & 0.1421 \\
\hline \multirow[t]{7}{*}{ Vector } & 0 & 0 & 0.0564 & 0.0977 \\
\hline & 5 & 0.021 & 0.0564 & 0.0977 \\
\hline & 10 & 0.021 & 0.0564 & 0.0977 \\
\hline & 15 & 0.017 & 0.0564 & 0.0977 \\
\hline & 20 & 0.017 & 0.0564 & 0.0977 \\
\hline & 25 & 0.033 & 0.0564 & 0.0977 \\
\hline & 30 & 0.021 & 0.0564 & 0.0977 \\
\hline
\end{tabular}

Linear regression to determine slopes from estimate values.

Calculations performed with $R$ software (version 3.2.2) (R Core Team, 2015)

\begin{tabular}{llll} 
Sample & Mean slope & SD & N \\
\hline IDH2 ${ }^{W T}$ & 0.01 & 0.090 & 3 \\
\hline IDH2 $^{\text {R172K }}$ & 0.06 & 0.140 & 3 \\
\hline Vector & 0.67 & 0.280 & 3 \\
\hline
\end{tabular}

Summary of original data estimated from graph reported in Figure 2B:

- $S D$ was calculated using formula $S D=S E M *(S Q R T(n))$, where $n=3$.

\begin{tabular}{llllr} 
Sample & Time & Original_Value_Mean & SEM & SD \\
\hline IDH2WT & 0 & 0 & 0.0039 & 0.0067 \\
\hline 17 & -0.003 & 0.0060 & 0.0105 \\
\hline 33 & -0.004 & 0.0073 & 0.0126 \\
\hline 50 & -0.005 & 0.0102 & 0.0177 \\
\hline 71 & -0.006 & 0.0104 & 0.0181 \\
\hline 90 & -0.008 & 0.0114 & 0.0198 \\
\hline 112 & -0.009 & 0.0117 & 0.0202 \\
\hline 131 & -0.01 & 0.0075 & 0.0130 \\
\hline 171 & -0.014 & 0.0121 & 0.0211 \\
\hline
\end{tabular}

Continued on next page 
Continued

\begin{tabular}{lllll} 
Sample & Time & Original_Value_Mean & SEM & SD \\
\hline IDH2 ${ }^{\text {R172K }}$ & 0 & 0 & 0.0039 & 0.0067 \\
\hline 17 & -0.006 & 0.0039 & 0.0067 \\
\hline 33 & -0.009 & 0.0065 & 0.0114 \\
\hline 50 & -0.016 & 0.0085 & 0.0147 \\
\hline 71 & -0.024 & 0.0080 & 0.0139 \\
\hline 90 & -0.028 & 0.0087 & 0.0152 \\
\hline 112 & -0.036 & 0.0095 & 0.0164 \\
\hline 131 & -0.043 & 0.0104 & 0.0181 \\
\hline 171 & -0.055 & 0.0095 & 0.0164 \\
\hline 0 & 0 & 0.0026 & 0.0046 \\
\hline 17 & 0.001 & 0.0026 & 0.0046 \\
\hline 33 & 0 & 0.0026 & 0.0046 \\
\hline 50 & 0 & 0.0026 & 0.0046 \\
\hline 71 & 0 & 0.0026 & 0.0046 \\
\hline 90 & 0 & 0.0026 & 0.0046 \\
\hline 112 & -0.002 & 0.0026 & 0.0046 \\
\hline 131 & -0.002 & 0.0026 & 0.0046 \\
\hline 171 & -0.003 & 0.0026 & 0.0046 \\
\hline & & &
\end{tabular}

Linear regression to determine slopes from estimates values.

Calculations performed with $R$ software (version 3.2.2) (R Core Team, 2015)

\begin{tabular}{llll} 
Sample & Mean slope & SD & N \\
\hline IDH2WT & -0.0006 & 0.005 & 3 \\
\hline IDH2 ${ }^{\text {R172K }}$ & -0.0241 & 0.013 & 3 \\
\hline Vector & -0.0065 & 0.016 & 3 \\
\hline
\end{tabular}

Test family

- One-way ANOVA: Fixed effects, omnibus, one-way: Bonferroni correction: alpha error = 0.025 .

\section{Power calculations}

- Power calculations were performed using G*Power, version 3.1.7 (Faul et al., 2007).

- ANOVA F test statistic and partial $\eta^{2}$ performed with R software, version 3.2.2 (R Core Team, 2015).

\begin{tabular}{|c|c|c|c|c|c|}
\hline Groups & F test statistic & Partial $\eta^{2}$ & Effect size $f$ & A priori power & Total sample siz \\
\hline $\begin{array}{l}\text { Slopes of NADPH } \\
\text { production from } \\
\text { IDH2 }{ }^{\text {WT }}, \text { IDH2 }{ }^{\mathrm{R} 172} \\
\text { or Vector (Figure 2A) }\end{array}$ & $F(2,6)=10.8$ & 0.7826 & 1.897636 & $99.99 \%^{1}$ & $\begin{array}{l}21^{1} \\
\text { (3 groups) }\end{array}$ \\
\hline $\begin{array}{l}\text { Slopes of } \mathrm{NADP}^{+} \\
\text {production from } \\
\text { IDH2 } 2^{\mathrm{WT}}, \mathrm{IDH}^{\mathrm{R} 172}, \\
\text { or Vector (Figure 2B) }\end{array}$ & $F(2,6)=3.02$ & 0.5023 & 1.0048 & $94.13 \%^{1}$ & $21^{1}$ (3 groups) \\
\hline
\end{tabular}

17 samples per group will be used based on the planned comparisons making the power at least $80 \%$. 


\section{Test family}

- 2 tailed $t$ test, Wilcoxon-Mann-Whitney test, Bonferroni's correction: alpha error $=0.0125$

Power Calculations performed with G*Power software, version 3.1.7 (Faul et al., 2007).

Figure 2A (NADPH production) values

\begin{tabular}{llllll} 
Group 1 & Group 2 & Effect size d & A priori power & Group 1 sample size & Group 2 sample size \\
\hline Vector & $\mathrm{IDH} 2^{\mathrm{WT}}$ & 3.05134 & $98.8 \%^{1}$ & $7^{1}$ & $7^{1}$ \\
\hline Vector & $\mathrm{IDH}^{\mathrm{R} 172 \mathrm{~K}}$ & $2.12463^{2}$ & $80.0 \%^{2}$ & 7 & 7
\end{tabular}

17 samples per group will be used based on the Vector vs IDH2 ${ }^{\mathrm{R} 172 \mathrm{~K}} \mathrm{NADP}^{+}$planned comparison making the power $98.8 \%$.

${ }^{2}$ A sensitivity calculation was performed since the original data showed a non-significant effect. This is the effect size that can be detected with $80 \%$ power and the indicated sample size. The original effect size reported was 0.49386 .

Figure 2B (NADP ${ }^{+}$production) values

\begin{tabular}{llllll} 
Group 1 & Group 2 & Effect size d & A priori power & Group 1 sample size & Group 2 sample size \\
\hline Vector & $\mathrm{IDH}^{\mathrm{WT}}$ & $2.12463^{1}$ & $80.0 \%^{1}$ & 7 & 7 \\
\hline Vector & $\mathrm{IDH} 2^{\mathrm{R} 172 \mathrm{~K}}$ & 2.21471 & $89.3 \%$ & 7 & 7
\end{tabular}

${ }^{1}$ A sensitivity calculation was performed since the original data showed a non-significant effect. This is the effect size that can be detected with $80 \%$ power and the indicated sample size. The original effect size reported was 0.47369 .

\section{Test family}

- Due to the large variance, these parametric tests are only used for comparison purposes. To ensure an adequate sample size is used, the number is based on the non-parametric tests listed above.

- 2 tailed $t$ test, difference between two independent means, Bonferroni's correction: alpha error $=0.0125$

Power Calculations performed with G*Power software, version 3.1.7 (Faul et al., 2007).

Figure 2A (NADPH production) values

\begin{tabular}{llllll} 
Group 1 & Group 2 & Effect size d & A priori power & Group 1 sample size & Group 2 sample size \\
\hline Vector & $\mathrm{IDH} 2^{\mathrm{WT}}$ & 3.05134 & $99.2 \%^{1}$ & $7^{1}$ & $7^{1}$ \\
\hline Vector & $\mathrm{IDH}^{\mathrm{R} 172 \mathrm{~K}}$ & $2.03^{2}$ & $80.0 \%^{2}$ & 7 & 7
\end{tabular}

${ }^{1}$ Seven samples per group will be used based on the Vector vs IDH2 ${ }^{\mathrm{R} 172 \mathrm{~K}} \mathrm{NADP}^{+}$planned comparison making the power $98.8 \%$.

${ }^{2}$ A sensitivity calculation was performed since the original data showed a non-significant effect. This is the effect size that can be detected with $80 \%$ power and the indicated sample size. The original effect size reported was 0.33972 .

Figure 2B (NADP ${ }^{+}$production) values

\begin{tabular}{|c|c|c|c|c|c|}
\hline Group 1 & Group 2 & Effect size $d$ & A priori power & Group 1 sample size & Group 2 sample size \\
\hline Vector & $\mathrm{IDH} 2^{\mathrm{WT}}$ & $2.05829^{1}$ & $80.0 \%^{1}$ & 7 & 7 \\
\hline Vector & $\mathrm{IDH} 2^{\mathrm{R} 172 \mathrm{~K}}$ & 2.03 & $90.4 \%$ & 7 & 7 \\
\hline
\end{tabular}


${ }^{1}$ A sensitivity calculation was performed since the original data showed a non-significant effect. This is the effect size that can be detected with $80 \%$ power and the indicated sample size. The original effect size reported was 0.51213 .

\section{Protocol 2: Figure 3D}

Summary of original data

- Note: data estimated from published graphs

\begin{tabular}{lll} 
Sample & Mean intracellular 2-HG/glutamate & Assumed N \\
\hline Vector & 0.0105 & 3 \\
\hline $\mathrm{IDH}^{\mathrm{WT}}$ & 0.0102 & 3 \\
\hline $\mathrm{IDH} 2^{\mathrm{R} 172 \mathrm{~K}}$ & 1.2 & 3
\end{tabular}

Test family

- One way ANOVA followed by Bonferroni corrected planed comparisons:

- Power calculations:

- Vector vs. IDH2 $2^{\mathrm{R} 172 \mathrm{~K}}$

- IDH2 $2^{\mathrm{WT}}$ vs. IDH2 $2^{\mathrm{R} 172 \mathrm{~K}}$

- Sensitivity Calculations

- Vector vs. IDH2 ${ }^{\mathrm{WT}}$

\section{Power calculations}

- Power calculations were performed using GraphPad PRISM v6 and G*Power (version 3.1.7) (Faul et al., 2007)

- Because the data did not display variance, we have performed power calculations with a range of variances and an assumed $\mathrm{N}$ of 3 per group.

- $2 \%$ variance

ANOVA; $\alpha=0.05$

\begin{tabular}{lllll}
\hline $\mathrm{F}(2,6)$ & Partial eta2 & Effect size $f$ & Power & Total N \\
\hline 7370 & 0.999593 & 49.55807 & $>99.99 \%$ & $6^{*}$
\end{tabular}

Power calculations; $\alpha=0.05$

\begin{tabular}{lllll}
\hline Group 1 & Group 2 & Effect size d & Power & N/group \\
\hline Vector & $\mathrm{IDH}^{\mathrm{WT}}$ & 70.10710478 & $>99.99 \%$ & $2^{*}$ \\
\hline IDH2WT & $\mathrm{IDH}^{\mathrm{W}}{ }^{\mathrm{R} 172 \mathrm{~K}}$ & 70.08927663 & $>99.99 \%$ & $2^{*}$
\end{tabular}

Sensitivity Calculations; $\alpha=0.05$, powered to $80 \%$

\begin{tabular}{|c|c|c|c|c|}
\hline Group 1 & Group 2 & Effect size $d$ & Detectable $d$ & N/group \\
\hline Vector & $\mathrm{IDH} 2^{\mathrm{R} 172 \mathrm{~K}}$ & 1.449123183 & 0.2774844 & 3 \\
\hline
\end{tabular}

*With a minimum of 3 per group ( 9 total), achieved power is $>99.99 \%$.

- $15 \%$ variance

ANOVA; $\alpha=0.05$

\begin{tabular}{lllll}
\hline $\mathrm{F}(2,6)$ & Partial eta2 & Effect size $f$ & Power & Total N \\
\hline 131 & 0.977612 & 6.608085 & $99.99 \%$ & $6^{*}$ \\
\hline Power calculations; $\alpha=0.05$ & & & N/group \\
\hline Group 1 & Group 2 & Effect size d & Power & \\
\hline Continued
\end{tabular}

Continued on next page 
Continued

ANOVA; $\alpha=0.05$

\begin{tabular}{|c|c|c|c|c|}
\hline Vector & $\mathrm{IDH} 2^{\mathrm{WT}}$ & 9.347613971 & $98.65 \%$ & $2^{\star}$ \\
\hline IDH2 $2^{\mathrm{WT}}$ & $\mathrm{IDH} 2^{\mathrm{R} 172 \mathrm{~K}}$ & 9.345236884 & $98.65 \%$ & $2^{*}$ \\
\hline \multicolumn{5}{|c|}{ Sensitivity Calculations; $\alpha=0.05$, powered to $80 \%$} \\
\hline Group 1 & Group 2 & Effect size $d$ & Detectable d & N/group \\
\hline Vector & $\mathrm{IDH} 2^{\mathrm{R} 172 \mathrm{~K}}$ & 0.193216424 & 0.0539826 & 3 \\
\hline
\end{tabular}

*With a minimum of 3 per group ( 9 total), achieved power is $>99.99 \%$.

- $28 \%$ variance

ANOVA; $\alpha=0.05$

\begin{tabular}{|c|c|c|c|c|}
\hline$F(2,6)$ & Partial eta2 & Effect size $f$ & Power & Total N \\
\hline 37.60 & 0.926108 & 3.540235 & $98.61 \%$ & $6^{*}$ \\
\hline \multicolumn{5}{|c|}{ Power calculations; $\alpha=0.05$} \\
\hline Group 1 & Group 2 & Effect size $d$ & Power & N/group \\
\hline Vector & $\mathrm{IDH} 2^{\mathrm{WT}}$ & 5.007650342 & $99.28 \%$ & 3 \\
\hline $\mathrm{IDH} 2^{\mathrm{WT}}$ & $\mathrm{IDH} 2^{\mathrm{R} 172 \mathrm{~K}}$ & 5.006376902 & $99.28 \%$ & 3 \\
\hline \multicolumn{5}{|c|}{ Sensitivity Calculations; $\alpha=0.05$, powered to $80 \%$} \\
\hline Group 1 & Group 2 & Effect size d & Detectable d & $\mathrm{N} /$ group \\
\hline Vector & $\mathrm{IDH} 2^{\mathrm{R} 172 \mathrm{~K}}$ & 0.103508799 & 0.0511419 & 3 \\
\hline
\end{tabular}

*With a minimum of 3 per group (9 total), achieved power is $99.99 \%$.

- $40 \%$ variance

ANOVA; $\alpha=0.05$

\begin{tabular}{lllll}
\hline $\mathrm{F}(2,6)$ & Partial eta2 & Effect size & Power & Total N \\
\hline 18.43 & 0.860009 & 2.478571 & $85.73 \%$ & $6^{*}$ \\
\hline Power calculations; $\alpha=0.05$ & & & N/group \\
\hline Group 1 & Group 2 & Effect size d & Power & 3 \\
\hline Vector & IDH2 ${ }^{\text {WT }}$ & 3.505355239 & $88.73 \%$ & 3 \\
\hline IDH2WT & IDH2R172K & 4.205285771 & $96.37 \%$ & \\
\hline Sensitivity Calculations; & $\alpha=0.05$, powered to $80 \%$ & & & N/group \\
\hline Group 1 & Group 2 & Effect size d & Detectable d & 3 \\
\hline Vector & IDH2 & & \\
\hline
\end{tabular}

*With a minimum of 3 per group (9 total), achieved power is $99.92 \%$.

- In order to produce quantitative replication data, we will run the experiment three times. We will determine the standard deviation across the biological replicates and combine this with the reported value from the original study to simulate the original effect size. We will use this simulated effect size to determine the number of replicates necessary to reach a power of at least $80 \%$. We will then perform additional replicates, if required, to ensure that the experiment has more than $80 \%$ power to detect the original effect.

- Note: Simulation analysis was also conducted using randomly generated values based on the SD and variance desired. These data are comparable to what is seen above when using a parametric model approach. Also there may be a need to appropriately transform these data based on the scale of Figure 3D, and we have assumed that this is one representative sample and not averages of all the data showing no variance. This simulation will be loaded to the OSF (https://osf.io/8|4ea/). 


\section{Protocol 3: Figure 5C}

Summary of original data

- Note: data estimated from published graphs and log transformed. Data includes IDH ${ }^{\mathrm{WT}}$ (no mutations in IDH1 or IDH2), IDH1 ${ }^{\mathrm{R} 132 \mathrm{C} / \mathrm{G}}, \mathrm{IDH} 2^{\mathrm{Mutant}}\left(\mathrm{IDH} 2^{\mathrm{R} 172 \mathrm{~K}}\right.$ and IDH2 $\left.2^{\mathrm{R} 1400}\right)$

\begin{tabular}{lll} 
Sample & 2HG/glutamate & log(2HG/glut) \\
\hline $\mathrm{IDH}{ }^{\mathrm{WT}}$ (Constant) & 0.01 & -4.605 \\
\hline $\mathrm{IDH} 1^{\text {Mutant }}$ & 0.600 & -0.511 \\
\hline $\mathrm{IDH} 1^{\text {Mutant }}$ & 1.200 & 0.182 \\
\hline $\mathrm{IDH} 1^{\text {Mutant }}$ & 1.600 & 0.470 \\
\hline $\mathrm{IDH} 1^{\text {Mutant }}$ & 1.800 & 0.588 \\
\hline $\mathrm{IDH} 1^{\text {Mutant }}$ & 3.000 & 1.099 \\
\hline $\mathrm{IDH} 1^{\text {Mutant }}$ & 0.600 & -0.511 \\
\hline $\mathrm{IDH} 2^{\text {Mutant }}$ & 0.140 & -1.966 \\
\hline $\mathrm{IDH} 2^{\text {Mutant }}$ & 0.160 & -1.832 \\
\hline $\mathrm{IDH} 2^{\text {Mutant }}$ & 0.290 & -1.237 \\
\hline $\mathrm{IDH} 2^{\text {Mutant }}$ & 0.300 & -1.204 \\
\hline $\mathrm{IDH} 2^{\text {Mutant }}$ & 0.310 & -1.171 \\
\hline $\mathrm{IDH} 2^{\text {Mutant }}$ & 0.470 & -0.755 \\
\hline $\mathrm{IDH} 2^{\text {Mutant }}$ & 0.590 & -0.528 \\
\hline $\mathrm{IDH} 2^{\text {Mutant }}$ & 0.310 & -1.171
\end{tabular}

Test family

- One sample t-test comparing Constant and mutant IDH groups:

- Constant vs. IDH1 $1^{R 132 C / G}$

- Constant vs. IDH2 $2^{\text {mutant }}$ (grouped)

- Constant vs. IDH1/2 $2^{\text {mutant }}$ (grouped)

\section{Power calculations}

Power calculations were performed using $\mathrm{R}$ software version 3.2 .2 and $\mathrm{G}$ Power (version 3.1.7) (Faul et alı, 2007). Bonferroni corrected one-sample t-tests compared to. 01 (threshed as reported by original authors).

\begin{tabular}{lllll} 
Constant & Group & $\begin{array}{l}\text { Effect size } \\
\text { d }\end{array}$ & $\begin{array}{l}\text { A priori } \\
\text { power }\end{array}$ & $\begin{array}{l}\text { Group sample } \\
\text { size }\end{array}$ \\
\hline 0.01 & $\mathrm{IDH} 1^{\mathrm{R} 132 \mathrm{C} / \mathrm{G}}$ & 8.404 & $99.99 \%$ & 4 \\
\hline 0.01 & $\mathrm{IDH} 2^{\text {Mutant }}$ & 6.746 & $99.99 \%$ & 4 \\
\hline 0.01 & $\mathrm{IDH} 1 / 2^{\text {Mutant }}$ & 4.361 & $99.99 \%$ & 4
\end{tabular}

- Because of the inherent complications that can occur when using primary patient cell lines, we have adjusted our sample size to four samples/group even though we achieve $>90 \%$ power when using three samples/group.

\section{Acknowledgements}

The Reproducibility Project: Cancer Biology core team would like to thank Courtney Soderberg at the Center for Open Science for assistance with statistical analyses. We would also like to thank 
Kermit L. Carraway III, Kacey Vandervorst, and Jason Hatakeyama from the Department of Biochemistry and Molecular Medicine at UC Davis and the UC Davis Comprehensive Cancer Center for methods consultation. The following companies generously donated reagents to the Reproducibility Project: Cancer Biology; American Type and Tissue Collection (ATCC), Applied Biological Materials, BioLegend, Charles River Laboratories, Corning Incorporated, DDC Medical, EMD Millipore, Harlan Laboratories, LI-COR Biosciences, Mirus Bio, Novus Biologicals, Sigma-Aldrich, and System Biosciences $(\mathrm{SBI})$.

\section{Additional information}

Group author details

Reproducibility Project: Cancer Biology

Elizabeth lorns: Science Exchange, Palo Alto, United States; William Gunn: Mendeley, London, United Kingdom; Fraser Tan: Science Exchange, Palo Alto, United States; Joelle Lomax: Science Exchange, Palo Alto, United States; Stephen Williams: Center for Open Science, Charlottesville, Virginia; Nicole Perfito: Science Exchange, Palo Alto, United States; Timothy Errington: Center for Open Science, Charlottesville, Virginia

Competing interests

OF, MRS: West Coast Metabolomics Center is a Science Exchange associated laboratory RP:CB: El, FT, JL, NP: Employed by and hold shares in Science Exchange Inc. The other authors declare that no competing interests exist.

Funding

The Reproducibility Project: Cancer Biology is funded by the Laura and John Arnold Foundation, provided to the Center for Open Science in collaboration with Science Exchange. The funder had no role in study design or the decision to submit the work for publication.

Author contributions

OF, MRS, CES-T, Drafting or revising the article; RP:CB, Conception and design, Drafting or revising the article

\section{References}

Bennett BD, Yuan J, Kimball EH, Rabinowitz JD. 2008. Absolute quantitation of intracellular metabolite concentrations by an isotope ratio-based approach. Nature Protocols 3:1299-1311. doi: 10.1038/nprot.2008. 107

Dang L, White DW, Gross S, Bennett BD, Bittinger MA, Driggers EM, Fantin VR, Jang HG, Jin S, Keenan MC, Marks KM, Prins RM, Ward PS, Yen KE, Liau LM, Rabinowitz JD, Cantley LC, Thompson CB, Vander Heiden MG, Su SM. 2009. Cancer-associated IDH1 mutations produce 2-hydroxyglutarate. Nature 462:739-744. doi: 10.1038/nature08617

Errington TM, lorns E, Gunn W, Tan FE, Lomax J, Nosek BA. 2014. An open investigation of the reproducibility of cancer biology research. eLife 3. doi: 10.7554/eLife.04333

Faul F, Erdfelder E, Lang A-G, Buchner A. 2007. G* power 3: a flexible statistical power analysis program for the social, behavioral, and biomedical sciences. Behavior Research Methods 39:175-191. doi: 10.3758/BF03193146

Figueroa ME, Abdel-Wahab O, Lu C, Ward PS, Patel J, Shih A, Li Y, Bhagwat N, Vasanthakumar A, Fernandez HF, Tallman MS, Sun Z, Wolniak K, Peeters JK, Liu W, Choe SE, Fantin VR, Paietta E, Löwenberg B, Licht JD, Godley LA, Delwel R, Valk PJM, Thompson CB, Levine RL, Melnick A. 2010. Leukemic IDH1 and IDH2 mutations result in a hypermethylation phenotype, disrupt TET2 function, and impair hematopoietic differentiation. Cancer Cell 18:553-567. doi: 10.1016/j.ccr.2010.11.015

Izquierdo-Garcia JL, Viswanath P, Eriksson P, Chaumeil MM, Pieper RO, Phillips JJ, Ronen SM. 2015. Metabolic reprogramming in mutant IDH1 glioma cells. PloS One 10:e0118781-16. doi: 10.1371/journal.pone.0118781

Jin G, Reitman ZJ, Spasojevic I, Batinic-Haberle I, Yang J, Schmidt-Kittler O, Bigner DD, Yan H. 2011. 2hydroxyglutarate production, but not dominant negative function, is conferred by glioma-derived NADPdependent isocitrate dehydrogenase mutations. PloS One 6:e16812-16818. doi: 10.1371/journal.pone.0016812

Juratli TA, Peitzsch M, Geiger K, Schackert G, Eisenhofer G, Krex D. 2013. Accumulation of 2-hydroxyglutarate is not a biomarker for malignant progression in IDH-mutated low-grade gliomas. Neuro-Oncology 15:682-690. doi: 10.1093/neuonc/not006 
Krell D, Mulholland P, Frampton AE, Krell J, Stebbing J, Bardella C. 2013. IDH mutations in tumorigenesis and their potential role as novel therapeutic targets. Future Oncology 9:1923-1935. doi: 10.2217/fon.13.143

Leonardi R, Subramanian C, Jackowski S, Rock CO. 2012. Cancer-associated isocitrate dehydrogenase mutations inactivate NADPH-dependent reductive carboxylation. The Journal of Biological Chemistry 287:14615-14620. doi: 10.1074/jbc.C112.353946

Lu C, Ward PS, Kapoor GS, Rohle D, Turcan S, Abdel-Wahab O, Edwards CR, Khanin R, Figueroa ME, Melnick A, Wellen KE, O'Rourke DM, Berger SL, Chan TA, Levine RL, Mellinghoff IK, Thompson CB. 2012. IDH mutation impairs histone demethylation and results in a block to cell differentiation. Nature 483:474-478. doi: 10.1038/ nature10860

Pusch S, Schweizer L, Beck A-C, Lehmler J-M, Weissert S, Miller AK, von Deimling A. 2014. D-2-hydroxyglutarate producing neo-enzymatic activity inversely correlates with frequency of the type of isocitrate dehydrogenase 1 mutations found in glioma. Acta Neuropathologica Communications 2:19-10. doi: 10.1186/2051-5960-2-19

R Core Team. 2015. R: A Language and Environment for Statistical Computing. Vienna, Austria: R Foundation for Statistical Computing. https://www.R-project.org

Ward PS, Cross JR, Lu C, Weigert O, Abel-Wahab O, Levine RL, Weinstock DM, Sharp KA, Thompson CB. 2012. Identification of additional IDH mutations associated with oncometabolite R(-)-2-hydroxyglutarate production. Oncogene 31:2491-2498. doi: 10.1038/onc.2011.416

Ward PS, Lu C, Cross JR, Abdel-Wahab O, Levine RL, Schwartz GK, Thompson CB. 2013. The potential for isocitrate dehydrogenase mutations to produce 2-hydroxyglutarate depends on allele specificity and subcellular compartmentalization. The Journal of Biological Chemistry 288:3804-3815. doi: 10.1074/jbc.M112.435495

Ward PS, Patel J, Wise DR, Abdel-Wahab O, Bennett BD, Coller HA, Cross JR, Fantin VR, Hedvat CV, Perl AE, Rabinowitz JD, Carroll M, Su SM, Sharp KA, Levine RL, Thompson CB. 2010. The common feature of leukemiaassociated IDH1 and IDH2 mutations is a neomorphic enzyme activity converting alpha-ketoglutarate to 2hydroxyglutarate. Cancer Cell 17:225-234. doi: 10.1016/j.ccr.2010.01.020

Xu W, Yang H, Liu Y, Yang Y, Wang P, Kim S-H, Ito S, Yang C, Wang P, Xiao M-T, Liu L-x, Jiang W-q, Liu J, Zhang J-y, Bin W, Frye S, Zhang Y, Xu Y-h, Lei Q-y, Guan K-L, Zhao S-m, Xiong Y. 2011. Oncometabolite 2hydroxyglutarate is a competitive inhibitor of $\alpha$-ketoglutarate-dependent dioxygenases. Cancer Cell 19:17-30. doi: 10.1016/j.ccr.2010.12.014

Zhao S, Lin Y, Xu W, Jiang W, Zha Z, Wang P, Yu W, Li Z, Gong L, Peng Y, Ding J, Lei Q, Guan K-L, Xiong Y. 2009. Glioma-derived mutations in IDH1 dominantly inhibit IDH1 catalytic activity and induce HIF-1alpha. Science 324:261-265. doi: 10.1126/science.1170944 